This is a non-peer reviewed preprint submitted to EarthArXiv

\title{
Performance of terrestrial laser scanning to characterize managed Scots pine (Pinus sylvestris L.) stands is dependent on forest structural variation
}

\author{
Tuomas Yrttimaa ${ }^{a, b}$, Ninni Saarinen ${ }^{b, a}$, Ville Kankare a,b, Jari Hynynen ${ }^{c}$, Saija Huuskonen ${ }^{c}$, \\ Markus Holopainen $^{b, d}$, Juha Hyyppä ${ }^{d}$, Mikko Vastaranta ${ }^{a}$ \\ a School of Forest Sciences, University of Eastern Finland, Joensuu, 80101, Finland \\ ${ }^{\mathrm{b}}$ Department of Forest Sciences, University of Helsinki, Helsinki, 00014, Finland \\ c Natural Resources Institute Finland (Luke), Helsinki, 00790, Finland \\ d Department of Remote Sensing and Photogrammetry, Finnish Geospatial Research Institute, National Land \\ Survey of Finland (NLS), Masala, 02431, Finland
}

Correspondence to: Tuomas Yrttimaa ${ }^{\mathrm{a}, \mathrm{b}}$ (tuomas.yrttimaa@uef.fi)

\begin{abstract}
There is a limited understanding of how forest structure affects the performance of methods based on terrestrial laser scanning (TLS) in characterizing trees and forest environments. We aim to improve this understanding by studying how different forest management activities that shape tree size distributions affect the TLS-based forest characterization accuracy in managed Scots pine (Pinus sylvestris L.) stands. For that purpose, we investigated 27 sample plots consisting of three different thinning types, two thinning intensities as well as control plots without any treatments. Multi-scan TLS point clouds were collected from the sample plots, and a point cloud processing algorithm was used to segment individual trees and classify the segmented point clouds into stem and crown points. The classified point clouds were further used to estimate tree and forest structural attributes. With the TLS-based forest characterization, almost $100 \%$ completeness in tree detection, $0.7 \mathrm{~cm}$ (3.4\%) root-mean-square-error (RMSE) in diameter-at-breast-height measurements, 0.9-1.4 m (4.5-7.3\%) RMSE in tree height measurements, and less than $6 \%$ relative RMSE in the estimates of forest structural attributes (i.e. mean basal area, number of trees per hectare, mean volume, basal area-weighted mean diameter and height) were obtained depending on the applied thinning type. Thinnings decreased variation in horizontal and vertical forest structure, which especially favoured the TLS-based tree detection and tree height measurements, enabling reliable estimates for forest structural attributes. A considerably lower performance was recorded for the control plots. Thinning intensity was noticed to affect more on the accuracy of TLS-based forest characterization than thinning type. The number of trees per hectare and the proportion of suppressed trees were recognized as the main factors affecting the accuracy of TLS-based forest characterization. The more variation there was in the tree size distribution, the more challenging it was for the TLS-based method to capture all the trees and derive the tree and forest structural attributes. In general, consistent accuracy and reliability in the estimates of tree and forest attributes can be expected when using TLS for characterizing managed boreal forests.
\end{abstract}

Keywords: LiDAR, remote sensing, forest inventory, point cloud, close-range, forest management

\section{INTRODUCTION}

Terrestrial laser scanning (TLS) is a powerful close-range sensing method for characterizing forests in three dimensions (3D; Dassot et al., 2011; Disney et al., 2018; Liang et al., 2016; Newnham et al., 2015). Individual trees can be identified from a TLS point cloud by detecting circular shapes (e.g. Aschoff et al., 2004; Maas et al., 2008) or clusters of points (e.g. Cabo et al., 2018; Zhang et al., 2019). These two approaches represent the most common tree detection methods implemented in forest applications (Liang et al., 2018). Then, depending on the algorithm used and the purpose of processing, the architectural structure of a tree stem (Heinzel \& Huber, 2016; Liang et al., 2012) or a whole tree (Hackenberg et al., 2014; Raumonen et al., 2013) can be reconstructed by using a series of geometrical primitives, preferably circular cylinders (Åkerblom et al., 2015). Tree reconstruction requires that points representing a tree are classified based on their origin, in other words from stem, branches, and foliage (Côté et al., 2012; Morsdorf et al., 2018). Classification algorithms for 
This is a non-peer reviewed preprint submitted to EarthArXiv

TLS-based point clouds are largely based on an assumption that stem points have more planar, vertical, and cylindrical characteristics than points originating from branches and foliage (Liang et al., 2012; Olofsson \& Holmgren, 2016; Raumonen et al., 2013; Yrttimaa, Saarinen, Kankare, et al., 2019). So far, there is only a limited number of classification approaches of TLS-based point clouds for separating wood and foliage based on geometric features (Vicari et al., 2019; D. Wang, 2020). With a careful TLS data collection and preprocessing, a single point in a TLS point cloud can reach a millimetre-level accuracy (Liang et al., 2018; Wilkes et al., 2017), meaning that the reconstructed tree models are geometrically highly accurate (Hackenberg et al., 2014). After the tree architecture is reconstructed for every tree in an area of interest, all the external tree dimensions can theoretically be derived for all the trees and further used in deriving the forest attributes of interest.

It is known that the accuracy of characterizing forests with TLS depends on the scanning setup, tree detection algorithm, algorithm for reconstructing tree structure, and completeness of a point cloud (i.e. visibility of trees in a point cloud; Gollob et al., 2019; Liang et al., 2018). Occlusion, causing incompleteness of a point cloud, is seen as the main source of error limiting the feasibility of TLS in characterizing forests (Abegg et al., 2017; Yrttimaa, Saarinen, Kankare, et al., 2019). A forest plot is commonly scanned from multiple locations, and the point clouds from individual scans are then registered together to minimize the proportion of occluded trees (Liang et al., 2016; Wilkes et al., 2017). However, the forest structure, such as different-sized trees and undergrowth vegetation consisting of both woody and leafy components, makes a TLS-based point cloud extremely complex (Côté et al., 2012; Disney et al., 2018; Morsdorf et al., 2018) and thus, occlusion is hard to be completely avoided. Occlusion effects are twofold. First, some of the trees remain undetected, which causes bias to the derived forest structural attributes, such as basal area and growing stock volume (Yrttimaa, Saarinen, Kankare, et al., 2019). Second, tree architectural structure cannot be fully reconstructed due to the limited number of points characterizing a tree, which leads to errors to the derived tree attributes, such as stem form and tree height (Y. Wang et al., 2019; Wan et al., 2019). Currently, there is a limited understanding of how forest structure affects the occlusion and further on the accuracy of the derived tree and forest structural attributes. It is, however, known that the amount of undergrowth vegetation, tree density, basal area, tree species, tree size distribution, and the number of branches all affect how well TLS is capable of characterizing a forest in general (Abegg et al., 2017; Liang et al., 2018; Olofsson \& Olsson, 2018; Yrttimaa, Saarinen, Kankare, et al., 2019). However, controlled experiments on each of these aspects are lacking. Furthermore, it is not known how much there is variation in the accuracy of a TLS-based method when characterizing forests within similar forest conditions, or how different forest management activities, which shape tree size distribution, affect the TLS-based forest characterization accuracy. When TLS is increasingly used in investigating, mapping, and monitoring managed forests its expected accuracy is imperative to be known.

The objective of this study is to examine how forest structure and especially different thinning treatments affect the performance of using TLS in characterizing forests. We investigated the accuracy of TLS-derived tree and forest structural attributes by using sample plots with controlled variation in forest structure. In our study design, we standardized the effect of 1) forest structure by placing the sample plots in stands that were harvested for research purposes with varying thinning type and intensity, 2) tree species by investigating pure Scots pine (Pinus sylvestris L.) stands, 3) scanning setup by using a similar multi-scan approach for all the sample plots, 4) the amount of undergrowth vegetation as it was removed from all the sample plots, and 5) point cloud processing algorithm by using state-of-the-art techniques. We aim to improve the understanding of how thinning intensity and type, which inherently affect the tree size distribution of the remaining trees, impact on characterizing managed Scots pine stands with TLS-based point clouds. For that purpose, we studied three thinning types along with two thinning intensities as well as control plots without any thinning treatments. In addition, we investigated how consistent results can be obtained for tree and forest structural attributes in similar forest conditions (i.e. by analysing the accuracy among sample plots with the same thinning type and intensity) with TLS-based point clouds.

\section{MATERIALS AND METHODS}

\subsection{Study materials}


This is a non-peer reviewed preprint submitted to EarthArXiv

\subsubsection{Study site and experimental design}

The study materials consist of field-measured tree inventory data and multi-scan TLS point cloud data collected from three study sites located in southern Finland (Pollari, $62^{\circ} 4.4^{\prime} \mathrm{N} 24^{\circ} 30.1^{\prime} \mathrm{E}$; Palomäki, $62^{\circ} 3.6^{\prime} \mathrm{N} 24^{\circ} 19.9^{\prime} \mathrm{E}$; Vesijako, $61^{\circ} 21.8^{\prime} \mathrm{N} 25^{\circ} 6.3^{\prime} \mathrm{E}$; see Fig. 1). The study sites represent managed, even-aged Scots pinedominated forest stands at the age of $\sim 50$ years. Each study site is characterized as mesic heath forest with relatively flat terrain and similar growth conditions. The elevation ranges from 120 to $155 \mathrm{~m}$ above the sea level and the temperature sum ranges from 1130 to $1256^{\circ}$ days. Nine rectangular sample plots with a size varying from $30 \mathrm{~m} \times 30 \mathrm{~m}\left(900 \mathrm{~m}^{2}\right)$ to $30 \mathrm{~m} \times 40 \mathrm{~m}\left(1200 \mathrm{~m}^{2}\right)$ were established for each study site in 2005 (Palomäki study site) and 2006 (Pollari and Vesijako study sites) by Natural Resources Institute Finland (Luke) resulting in 27 sample plots in total. The sample plots were initially established to investigate the effect of different thinning types and thinning intensities on the growth and development of Scots pine trees and the dynamics of Scots pine stands. Thus, the experimental design of the sample plots includes three thinning types (i.e. thinning from below, thinning from above, systematic thinning from above) with two levels of thinning intensity (i.e. moderate, intensive) resulting in six different thinning treatments (see (Saarinen et al., 2020)).

The thinning types represent different approaches to determine the trees to be removed. In thinning from below, suppressed and co-dominant trees were removed whereas in thinning from above mostly dominant trees were removed. In both thinning types, small and damaged trees were also removed, and the regular spatial distribution of the remaining trees was maintained. In systematic thinning from above, only dominant trees were removed. Small suppressed trees were left to grow and regularity of spatial distribution of remaining trees was not emphasized as much as in other thinning types. However, large openings were avoided. Thinning intensity refers to the proportion of basal area $\left(\mathrm{m}^{2} / \mathrm{ha}\right)$ removed during the thinning. Moderate thinning followed the prevailing thinning guidelines applied in Finland (Rantala, 2011) whereas intensive thinning corresponded to $50 \%$ lower remaining basal area than in the plots where moderate thinning intensity was applied (see Fig. 1).

At the time of establishment, the centre and the corners of each sample plot were marked in the field with wooden poles, and their exact locations were measured using VRS-corrected GNSS. The thinning treatments were applied for 24 sample plots to make three to five repetitions of each treatment in total. One sample plot from each study site was kept as a control plot with no treatments carried out since the establishment. The trees were numbered, and treemaps were constructed by locating the trees concerning the distance and the azimuth angle to the plot centre. Due to different treatments and trees' ability to adapt to changes in growth resources, the forest structure of the sample plots has been developed differently from similar starting conditions since the time of establishment (Table 1). 
This is a non-peer reviewed preprint submitted to EarthArXiv
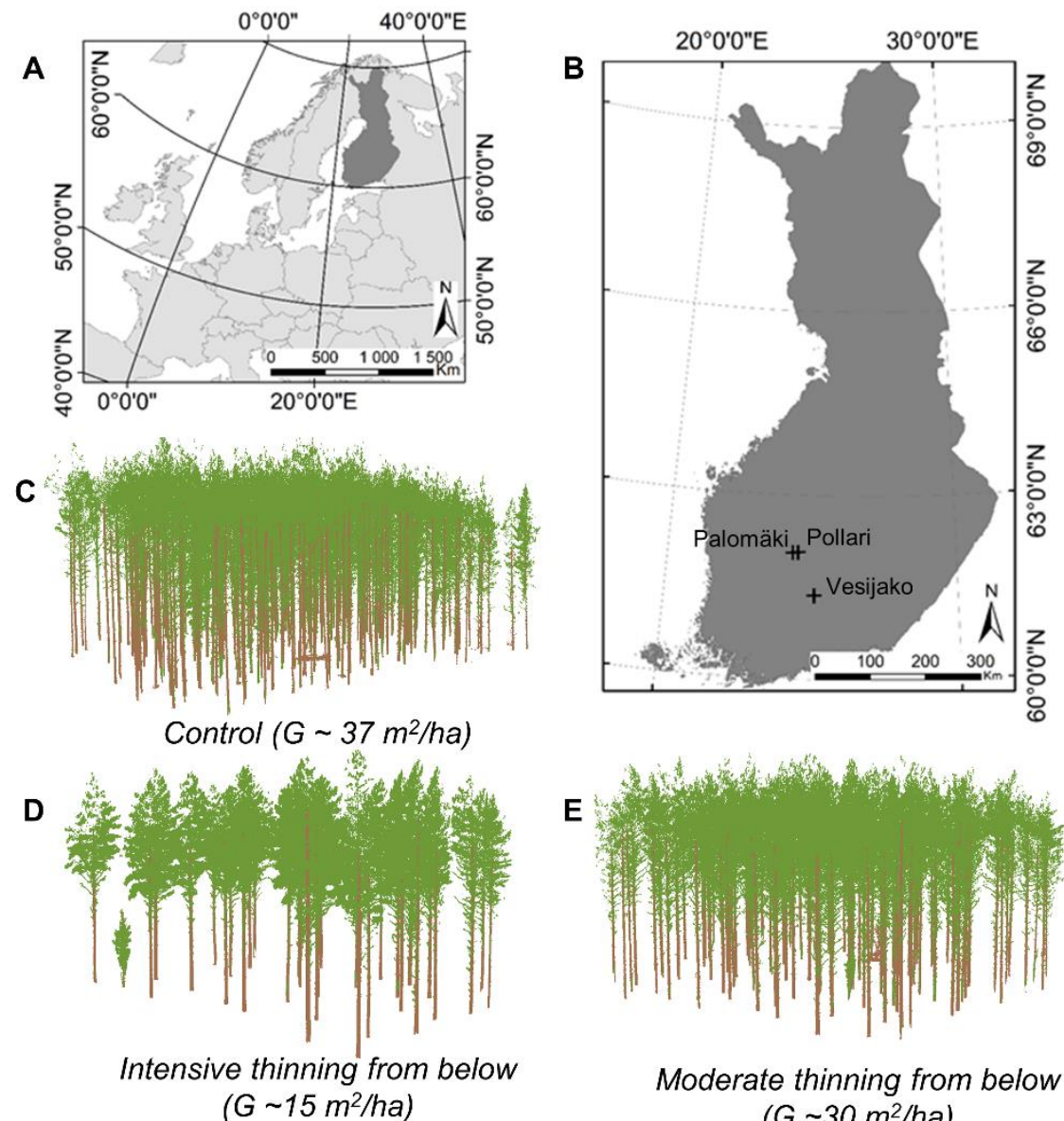

Moderate thinning from below ( $\mathrm{G} \sim 30 \mathrm{~m}^{2} / \mathrm{ha}$ )

Fig. 1. Location of the three study sites, namely Palomäki, Pollari, and Vesijako (A-B), as well as point cloud visualizations of the different thinning intensities: control (i.e. no treatments, $\mathrm{C}$ ), intensive thinning from below (D), and moderate thinning from below (E). G stands for the mean basal area.

\subsubsection{Field inventory}

Tree-wise field inventory was carried out in October 2018 and April 2019 to obtain reference measurements for all the 2204 trees on the sample plots. Tree species, crown layer (dominant, co-dominant, suppressed), and health status (alive, dead) were recorded from each tree within a plot (i.e. tally trees) using visual inspection. Diameter-at-breast-height (dbh) was measured for all the tally trees with steel callipers as an average of two diameter measurements perpendicular to each other at the height of $1.3 \mathrm{~m}$ above the ground. About half of the trees (928) were selected as sample trees for which tree height, the height of the crown base, and the height of the lowest dead branch were also measured using an electronic clinometer. Heights of the tally trees were estimated with allometric models that were calibrated for each sample plot using the sample trees. Stem volume was estimated for all the trees using nationwide, species-specific volume equations with $\mathrm{dbh}$ and tree height as explanatory variables (Laasasenaho, 1982). The plot-level forest structural attributes, namely basal area-weighted mean diameter $\left(D_{g}\right)$ and height $\left(H_{g}\right)$, mean basal area $(G)$, the number of trees per hectare $(\mathrm{TPH})$, and mean volume $\left(\mathrm{V}_{\text {mean }}\right)$ were then aggregated from the tree attributes according to Equations 1-5:

$$
\begin{aligned}
& D_{g}=\frac{\sum_{i=1}^{n} d_{i} g_{i}}{\sum_{i=1}^{n} g_{i}} \\
& H_{g}=\frac{\sum_{i=1}^{n} h_{i} g_{i}}{\sum_{i=1}^{n} g_{i}}
\end{aligned}
$$


This is a non-peer reviewed preprint submitted to EarthArXiv

$$
\begin{gathered}
G=\frac{\sum_{i=1}^{n} h_{i} g_{i}}{A} \\
T P H=\frac{n}{A} \\
V_{\text {mean }}=\frac{\sum_{i=1}^{n} v_{i}}{A}
\end{gathered}
$$

where $n$ is the number of trees in a sample plot, $d_{i}$ is the $\mathrm{dbh}$ of the $i^{\text {th }}$ tree, $g_{i}$ is the basal area of the $i^{\text {th }}$ tree, $h_{i}$ is the height for the $i^{\text {th }}$ tree, A is the area of the sample plot in hectares, and $v_{i}$ is the stem volume of the $i^{\text {th }}$ tree.

Table 1. Variation in forest structural attributes of the 27 sample plots by thinning types and intensities based on field inventory data acquired in October 2018 and April 2019. $D_{g}=$ basal area-weighted mean diameter $(\mathrm{cm}), \mathrm{H}_{\mathrm{g}}=$ basal area-weighted mean height $(\mathrm{m}), \mathrm{G}=$ mean basal area $\left(\mathrm{m}^{2} / \mathrm{ha}\right), \mathrm{TPH}=$ trees per hectare

\begin{tabular}{|c|c|c|c|c|c|}
\hline $\begin{array}{l}\text { Forest } \\
\text { structural } \\
\text { attribute }\end{array}$ & Thinning type & $\begin{array}{l}\text { Minimum } \\
\text { (mod. / int.) }\end{array}$ & $\begin{array}{c}\text { Mean } \\
\text { (mod. / int.) }\end{array}$ & $\begin{array}{l}\text { Maximum } \\
\text { (mod. / int.) }\end{array}$ & $\begin{array}{l}\text { Standard Deviation } \\
\text { (mod. / int.) }\end{array}$ \\
\hline \multirow{4}{*}{$D_{g}(\mathrm{~cm})$} & Thinning from below & $21.0 / 25.5$ & $23.5 / 27.5$ & $25.3 / 31.1$ & $2.2 / 3.1$ \\
\hline & Thinning from above & $18.4 / 19.7$ & $21.2 / 22.3$ & $22.8 / 24.9$ & $1.9 / 2.1$ \\
\hline & Systematic thinning & $19.0 / 17.7$ & 20.6 / 22.2 & $21.6 / 25.1$ & $1.2 / 3.0$ \\
\hline & Control & 18.1 & 21.0 & 23.8 & 2.9 \\
\hline \multirow{4}{*}{$H_{g}(\mathrm{~m})$} & Thinning from below & 19.4 / 20.5 & $21.7 / 21.6$ & 23.2 / 23.5 & $2.0 / 1.6$ \\
\hline & Thinning from above & $19.8 / 18.1$ & $21.0 / 19.5$ & 22.2 / 20.7 & $1.1 / 1.2$ \\
\hline & Systematic thinning & $18.5 / 16.9$ & $20.3 / 20.0$ & $22.2 / 21.9$ & $1.4 / 2.2$ \\
\hline & Control & 18.2 & 21.4 & 24.6 & 3.2 \\
\hline \multirow{4}{*}{$G\left(\mathrm{~m}^{2} / \mathrm{ha}\right)$} & Thinning from below & $26.9 / 15.4$ & $28.4 / 15.9$ & $31.3 / 16.7$ & $2.5 / 0.7$ \\
\hline & Thinning from above & $27.0 / 15.2$ & $28.3 / 16.1$ & $29.2 / 17.8$ & $0.9 / 1.2$ \\
\hline & Systematic thinning & $25.0 / 13.3$ & $27.5 / 15.8$ & $29.3 / 17.7$ & $1.6 / 1.8$ \\
\hline & Control & 33.6 & 37.7 & 43.3 & 5.1 \\
\hline \multirow{4}{*}{$\begin{array}{c}\mathrm{TPH} \\
(\mathrm{n} / \mathrm{ha})\end{array}$} & Thinning from below & $625 / 215$ & $705 / 287$ & $835 / 340$ & $113 / 65$ \\
\hline & Thinning from above & 747 / 336 & 917 / 446 & 1229 / 528 & $213 / 82$ \\
\hline & Systematic thinning & 804 / 320 & 945 / 462 & $1083 / 742$ & $111 / 174$ \\
\hline & Control & 1240 & 1312 & 1448 & 118 \\
\hline \multirow{4}{*}{$\begin{array}{c}V_{\text {mean }} \\
\left(\mathrm{m}^{3} / \mathrm{ha}\right)\end{array}$} & Thinning from below & $251.0 / 151.5$ & 291.8 / 160.8 & 339.7 / 169.6 & $44.8 / 9.1$ \\
\hline & Thinning from above & $273.8 / 133.1$ & $282.5 / 150.5$ & $289.0 / 160.8$ & $6.4 / 12.6$ \\
\hline & Systematic thinning & $245.9 / 133.8$ & $267.0 / 149.3$ & $283.0 / 162.4$ & $14.4 / 11.6$ \\
\hline & Control & 297.7 & 388.9 & 501.2 & 103.4 \\
\hline
\end{tabular}
$(\mathrm{n} / \mathrm{ha}), \mathrm{V}_{\text {mean }}=$ mean volume $\left(\mathrm{m}^{3} / \mathrm{ha}\right)$, mod. $=$ moderate thinning intensity, and int. $=$ intensive thinning intensity.

\subsubsection{Terrestrial laser scanning data acquisition}

The TLS data were collected using a Trimble TX5 3D (Trimble Inc., Sunnyvale, California, United States) phase-shift scanner that operates at a 1550-nm wavelength and measures 976,000 points per second, 
This is a non-peer reviewed preprint submitted to EarthArXiv

delivering a hemispherical $\left(300^{\circ}\right.$ vertical $\times 360^{\circ}$ horizontal) point cloud with an angular resolution of $0.009^{\circ}$ in both vertical and horizontal direction. A multi-scan approach was used in the TLS campaign to ensure point cloud quality and completeness with sufficient digitization of the trees within the sample plots. The scan setup consisted of two centre scans placed a few meters apart from each other near the plot centre, and six auxiliary scans placed closer to the plot borders making eight scanning locations in total (Saarinen et al., 2020) (see Fig. 1). At each scan location, the scanner was placed on a tripod approximately at the height of $1.6-1.8 \mathrm{~m}$ from the ground. Constant-sized spheres with a radius of $198 \mathrm{~mm}$ were used as the reference targets for registering and merging the point clouds from each scan location by following a similar procedure used in e.g. (Yrttimaa, Saarinen, Luoma, et al., 2019). The point cloud registration was carried out using FARO Scene software (version 2018) with a mean distance error of $2.9 \mathrm{~mm}$ and standard deviation $1.2 \mathrm{~mm}$, mean horizontal error of $1.3 \mathrm{~mm}$ (standard deviation $0.4 \mathrm{~mm}$ ) and mean vertical error of $2.3 \mathrm{~mm}$ (standard deviation $1.2 \mathrm{~mm}$ ). The overall point density of the registered multi-scan point cloud was $52,000-91,000$ points $/ \mathrm{m}^{2}$ depending on the structure of a sample plot.

\subsection{Deriving tree and forest structural attributes from point clouds}

\subsubsection{General description}

An automatic method for processing the TLS point clouds was used in this study to segment trees, classify the point clouds into stem and crown points, and to estimate tree and forest structural attributes from the merged multi-scan TLS point clouds. The outline of the method is presented in Fig. 2 and explained in detail in the following sections.

\subsubsection{Canopy segmentation}

First, the multi-scan TLS point clouds were partitioned into crown segments using a simple raster-based canopy segmentation procedure (Fig. 2 a). Canopy height models (CHMs) at a $20-\mathrm{cm}$ resolution were generated from the height-normalized TLS point clouds using the LAStools software (Isenburg, 2019). Preliminary locations of treetops were identified from the CHMs by applying a Variable Window Filter approach (Popescu \& Wynne, 2004). Then, a Marker-Controlled Watershed Segmentation (Meyer \& Beucher, 1990) was used to delineate canopy segments (polygons) that were used in extracting the crown segments from the TLS point clouds. A point-in-polygon approach was applied on XY-plane to determine the group of points belonging to each crown segment. This way the TLS point clouds were partitioned into smaller samples, each sample representing a tree, or a small group of trees if the crowns of adjacent trees were overlapping. The point cloud sampling enabled the use of parallel processing techniques to speed up computations in further stages of the processing workflow.

\subsubsection{Point cloud classification}

The crown-segmented point clouds were further classified into stem points and non-stem points using a pointcloud classification approach developed in this study (Fig. 2b). The classification was based on a general assumption that stem points have more planar, vertical, and cylindrical characteristics than points representing branches and foliage (Liang et al., 2012; Yrttimaa, Saarinen, Kankare, et al., 2019). The proposed method is an iterative procedure starting from the base of a tree stem and proceeding towards the top of the tree. Thus, the tree segment was first partitioned into $n$ number of horizontal point cloud slices $P_{1} \ldots P_{n}$. The first slice, $P_{1}$ was delineated between the heights of $0 \mathrm{~m}$ and $4 \mathrm{~m}$ to access the stem origin. From $P_{2}$ upwards the point cloud was binned at $50-\mathrm{cm}$ vertical intervals until the treetop was reached. For each point cloud bin, the following procedure was repeated to identify stem points and non-stem points: 1) Grid average downsampling, 2) Surface normal filtering, 3) Point clustering, 4) Random sample consensus (RANSAC)-cylinder filtering, and 5) Stem points and non-stem points extraction (Fig. 2b).

The binned point cloud was first sampled to uniform the point spacing using a grid-average-downsampling method with a grid size of $5 \mathrm{~mm}$. Surface normal vectors were computed for the downsampled points according to their 40 neighbour points to extract points on vertical surfaces (i.e. horizontal normal vector orientation). Vertical surface points were then segmented into clusters with a minimum of $30 \mathrm{~cm}$ Euclidean distance between points from different clusters. It was assumed that stem points compose of larger vertical clusters compared to non-stem points. Thus, clusters containing the minimum acceptable number of points $m$ and with 
This is a non-peer reviewed preprint submitted to EarthArXiv

a vertical dimension exceeding the set minimum value $k$ were classified as candidate stem points. The values for $m$ and $k$ were 100 points and $1 \mathrm{~m}$ for $P_{1}$ and 40 points and $30 \mathrm{~cm}$ for $P_{2} \ldots P_{n}$. The values for these parameters should be set based on the scan setup, realized point cloud density, and a prior knowledge on the range of tree heights. However, it should be noted that in our preliminary investigations the method was not sensitive to the parameter values used. Due to overlapping canopies, there might be multiple trees inside a tree segment. Therefore, in the case of $P_{1}$, the point cloud clustering procedure was repeated using a $50-\mathrm{cm}$ Euclidean distance threshold to separate those trees from each other.

A RANSAC-cylinder filtering procedure was then applied for the candidate stem points to ensure that the identified stem point clusters represent the cylindrical form of a tree stem. The filtering procedure was based on the RANSAC-algorithm (Bolles \& Fischler, 1981), which is commonly used when estimating parameters for mathematical models fitted in a data set that has outliers. A RANSAC-cylinder was fitted into the candidate stem points, and points within the surface of the fitted cylinder were considered as inliers. Points with more than $1.5-\mathrm{cm}$ Euclidean distance from the cylinder surface were considered as outliers and removed. The fitted cylinder was forced to be vertical, and the radius of the cylinder was allowed to vary within a prescribed range from 2.5 to $25.0 \mathrm{~cm}$ based on a priori knowledge from the field inventory.

An alpha shape was then created to envelope the identified stem points. Points of the original, non-sampled point cloud bin that fell inside the alpha shape were classified as stem points while points that fell outside the alpha shape were classified as non-stem points. After completing the classification in bin $P_{i}$, the procedure proceeded to bin $P_{i+1}$ where the parameters (XY-location, orientation, radius) of the fitted RANSAC-cylinder in $P_{i}$ were used to guide the point classification.

\subsubsection{Tree attribute extraction and aggregation of plot-level forest structural attributes}

Tree attributes, namely dbh, tree height, and stem volume, were extracted from the classified point clouds following the procedure originally presented in (Yrttimaa, Saarinen, Kankare, et al., 2019) (Fig. 2c). Tree height was determined as the vertical distance between the highest and lowest points for each tree. Stem taper curve was estimated by measuring diameters through circle fitting to the stem points at $20-\mathrm{cm}$ vertical intervals. The outliers in diameter-height -observations were filtered out by comparing the estimated diameters to the mean of three previous (or three closest at the bottom of the stem) diameters. Then a cubic spline curve was fitted to the diameter-height -observations to level unevenness in diameter estimates and to interpolate the missing diameters, as proposed in (Saarinen et al., 2017). Dbh was then obtained as the diameter at a 1.3-m height from the estimated taper curve. Stem volume was estimated by considering the stem as a sequence of vertical cylinders and aggregating their volume (Fig. 2c). Finally, the plot-level forest structural attributes (i.e., $\mathrm{D}_{g}, \mathrm{H}_{g}$, $\mathrm{G}, \mathrm{TPH}$, and $\mathrm{V}_{\text {mean }}$ ) were computed by aggregating the tree attributes at the plot level according to the Equations 1-5. 
This is a non-peer reviewed preprint submitted to EarthArXiv

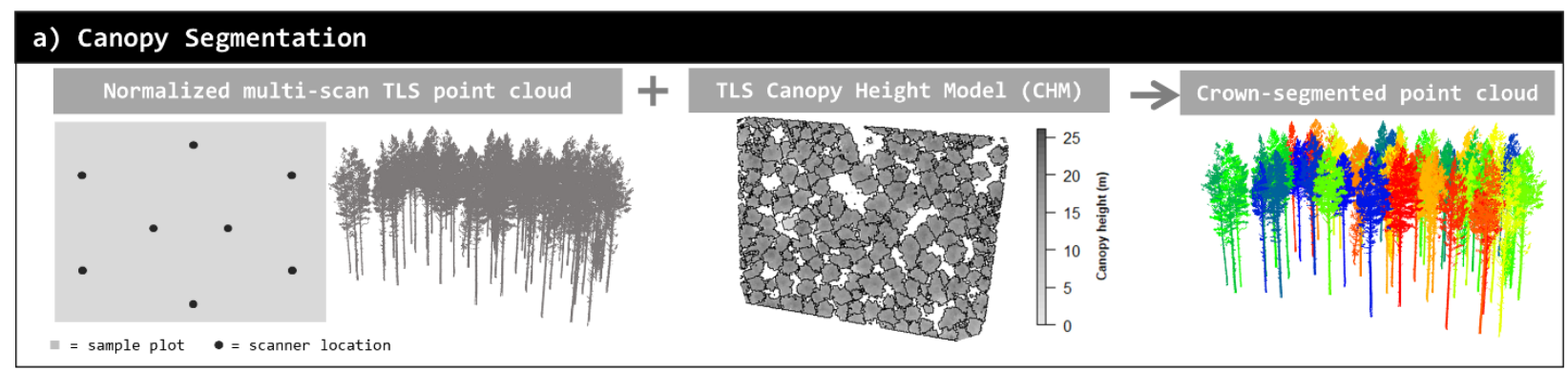

b) Point Cloud Classification

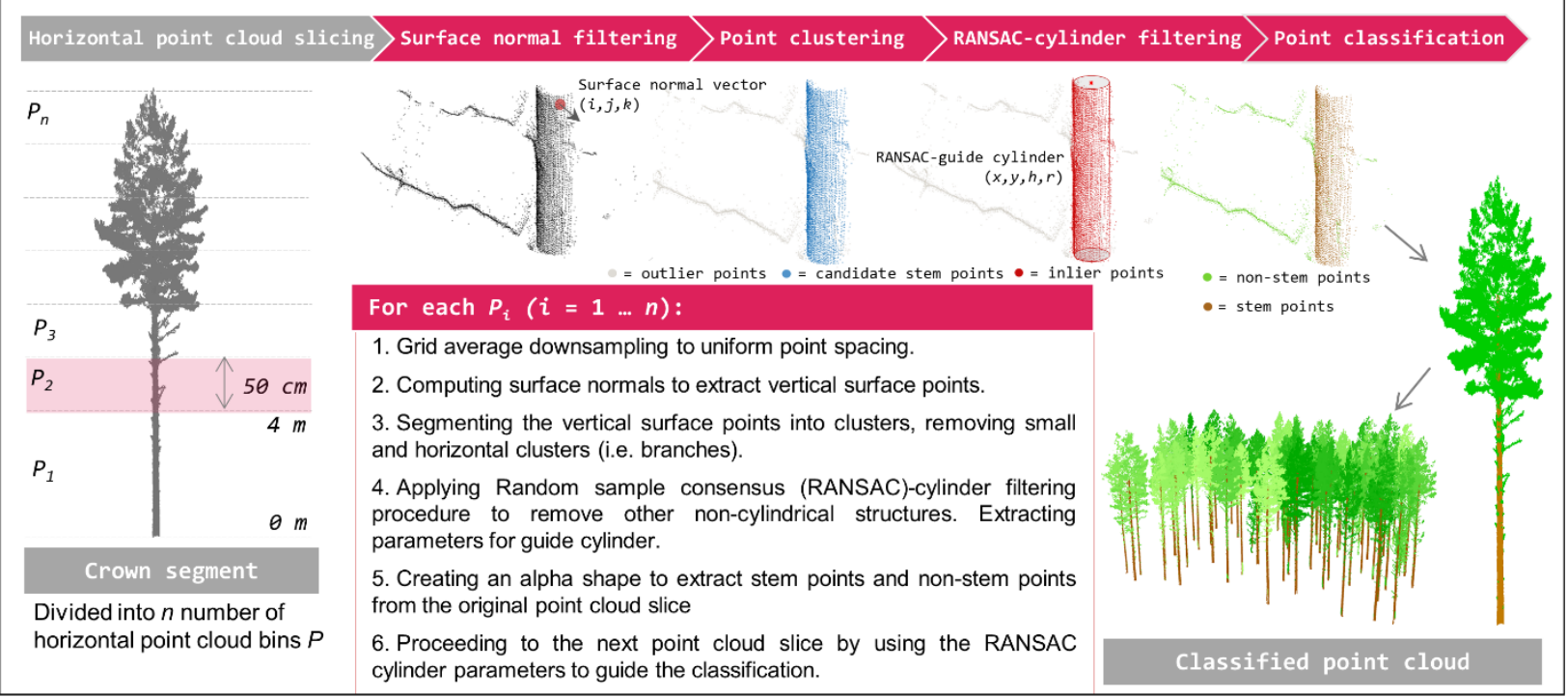

c) Tree Attribute Extraction

$\begin{aligned} & \text { Taper curve } \\ & \text { between the highest } \\ & \text { and lowest point }\end{aligned}$
$\begin{aligned} & \text { Diameter at } 1.3 \mathrm{~m} \\ & \text { height, obtained from } \\ & \text { the taper curve }\end{aligned}$

Fig. 2. Outline of the TLS data processing workflow. Two centre scans and six auxiliary scans were used to acquire a multi-scan TLS point cloud data. TLS-based canopy height model (CHM) and a Marker-Controlled Watershed Segmentation procedure were applied to normalized TLS point clouds to detect individual trees

(a). Horizontal point cloud slicing, surface normal filtering, point cloud clustering and Random Sample

Consensus (RANSAC)-based cylinder filtering were applied to identify vertical, cylindrical, and planar surfaces to classify TLS point cloud into stem and non-stem points (b). Then, the classified point cloud was used to extract tree attributes, namely diameter-at-breast-height (dbh), tree height (h), and stem volume (V) through taper curve modelling (c). Tree attributes were then aggregated at the sample plot level to obtain estimates for the forest structural attributes (see Eq. 1-5).

\subsection{Assessing the performance of the TLS-based forest characterization}

Performance of the TLS-based method to characterize forest structure was assessed by comparing the TLS point cloud-derived tree attributes (dbh and tree height) and plot-level forest structural attributes $\left(D_{g}, H_{g}, G\right.$, 
This is a non-peer reviewed preprint submitted to EarthArXiv

$\mathrm{TPH}, \mathrm{V}_{\text {mean }}$ ) with the field-measured ones by using bias (mean error) and root-mean-square-error (RMSE) as accuracy measures:

$$
\begin{aligned}
\text { bias } & =\frac{\sum_{i=1}^{n}\left(\widehat{X}_{l}-X_{i}\right)}{n} \\
R M S E & =\sqrt{\frac{\sum_{i=1}^{n}\left(\widehat{X}_{l}-X_{i}\right)^{2}}{n}}
\end{aligned}
$$

where $n$ is the number of trees or sample plots, $\widehat{X}_{l}$ is the TLS point cloud-derived tree attribute or forest structural attribute for plot $i$, and $X_{i}$ is the corresponding attribute based on field measurements.

Accuracy of the TLS-based forest characterization is affected by the capability of the method to detect trees from the point clouds (Liang et al., 2018; Yrttimaa, Saarinen, Kankare, et al., 2019). Therefore, we also analysed the tree detection accuracy at the plot level using completeness and correctness as accuracy measures. Completeness indicates the percentage of trees detected from the point clouds, whereas correctness measures the percentage of TLS-derived trees that were correctly matched with the reference (see e.g. Liang et al., 2018). At the plot level, completeness indicates the tree detection rate, or how large a part of the field-measured TPH is detected from the point clouds.

To reveal the effects of thinning treatments on the performance of the TLS-based forest characterization, the accuracy was assessed by thinning type and intensity. A one-sample $t$-test was used in pairwise investigations to examine whether the estimation error of tree and forest structural attributes in one thinning treatment significantly differed from the errors of the respective estimates of other thinning treatments.

In addition, we investigated how consistent results can be obtained with TLS for tree and forest structural attributes in similar forest conditions by analysing the variation in accuracy measures among sample plots with the same thinning type and intensity and comparing the range of variation in accuracy measures between different thinning treatments.

\section{RESULTS}

\subsection{Overall performance}

Out of the total number of 2102 Scots pine trees, 2076 (98.8\%) were automatically detected from the TLS point clouds. The stem volume of the detected trees accounted for $99.5 \%$ of the total stem volume of the Scots pine trees. Suppressed trees accounted for $48.2 \%$ of the trees that remained undetected from the points clouds, while the respective proportion in the whole tree population was only $4.5 \%$. The correctness of tree detection was $100 \%$, which indicated a robust performance of the TLS-based method in managed Scots pine forests.

On average, dbh and tree height were underestimated by $0.1 \mathrm{~cm}$ and $0.3 \mathrm{~m}$, respectively. RMSE in dbh estimates was $0.7 \mathrm{~cm}(3.4 \%)$ while in tree height estimates the RMSE was $1.6 \mathrm{~m}(8.4 \%)$. Accuracy in tree attribute extraction was similar for dominant and co-dominant trees while for suppressed trees the dbh (RMSE 9.3\%) and tree height (RMSE 18.5\%) were estimated less accurately.

Relative RMSEs of $<5.5 \%$ were recorded for all the forest structural attributes in all sample plots. On average, $V_{\text {mean }}$ was overestimated while the other attributes were underestimated. Erroneous tree height estimates seemed to compensate at the plot level as the $\mathrm{H}_{\mathrm{g}}$ was estimated more accurately (RMSE $0.65 \mathrm{~m}$ ) than the height of individual trees.

\subsection{The effects of thinning treatment on the performance of TLS-based approach}

Overall completeness of tree detection was at the same level for all the thinning types: $100 \%$ for thinning from below, $99.7 \%$ for thinning from above, and $99.4 \%$ for systematic thinning (Table 2). No significant differences $(p>0.05)$ was noticed in tree detection accuracy between different thinning treatments, including control plots. Tree detection accuracy slightly decreased when no treatments were applied to the sample plots being $95.6 \%$ for the control plots (Table 2). Field-measured and TLS-estimated dbh distributions (Fig. 3a-g) and tree height 
This is a non-peer reviewed preprint submitted to EarthArXiv

distributions (Fig. 4a-g) were similar regardless of thinning treatment. The few trees that remained undetected from the control plots mainly represented the small dbh and height classes (Figs. $3 g, 4 g$ ).

Table 2. Completeness and correctness of tree detection by thinning types and intensities.

\begin{tabular}{ccccc}
$\begin{array}{c}\text { Thinning type / } \\
\text { Intensity }\end{array}$ & $\begin{array}{c}\text { Completeness of tree detection (\%) } \\
\text { Moderate }\end{array}$ & Intensive & Moderate & Correctness of tree detection (\%) \\
\hline Thinning from below & 100 & 100 & 100 & 100 \\
\hline Thinning from above & 99.8 & 99.6 & 100 & 100 \\
\hline Systematic thinning & 98.7 & 99.8 & & 100 \\
\hline Control & & 95.6 & & 100 \\
\hline
\end{tabular}
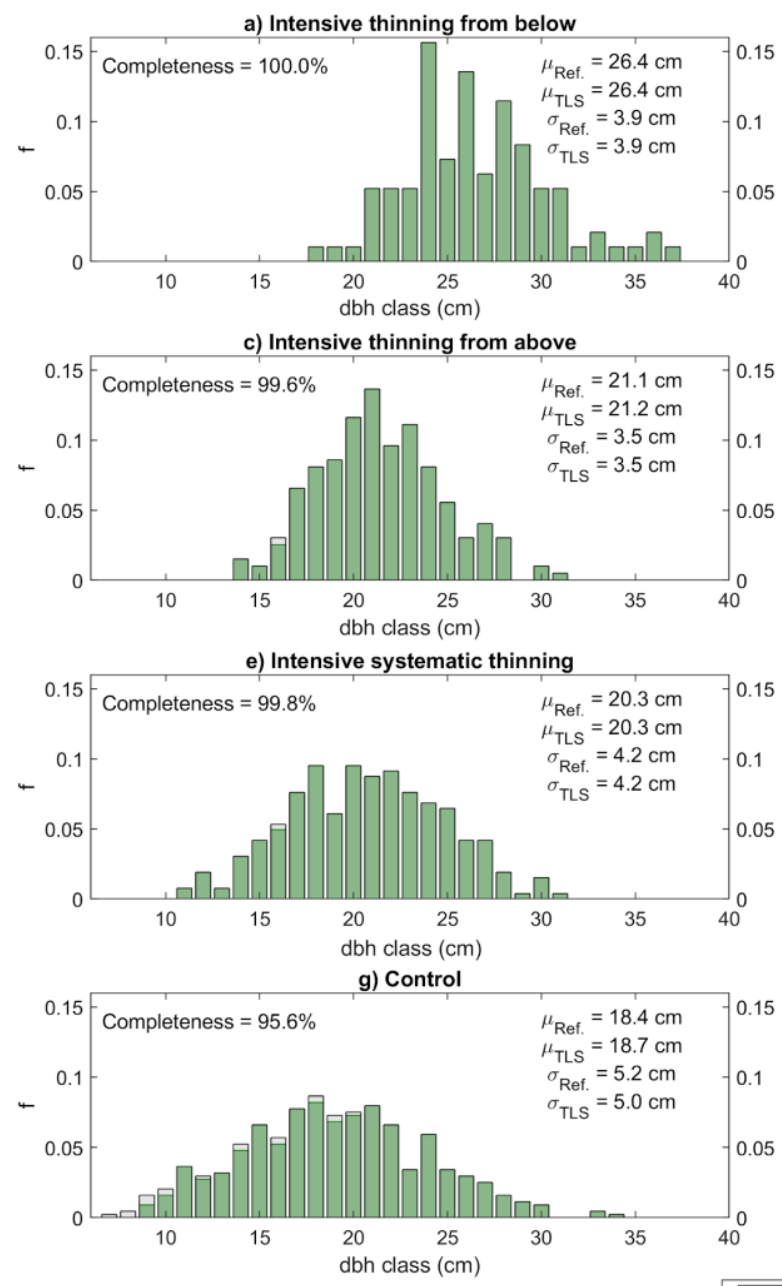
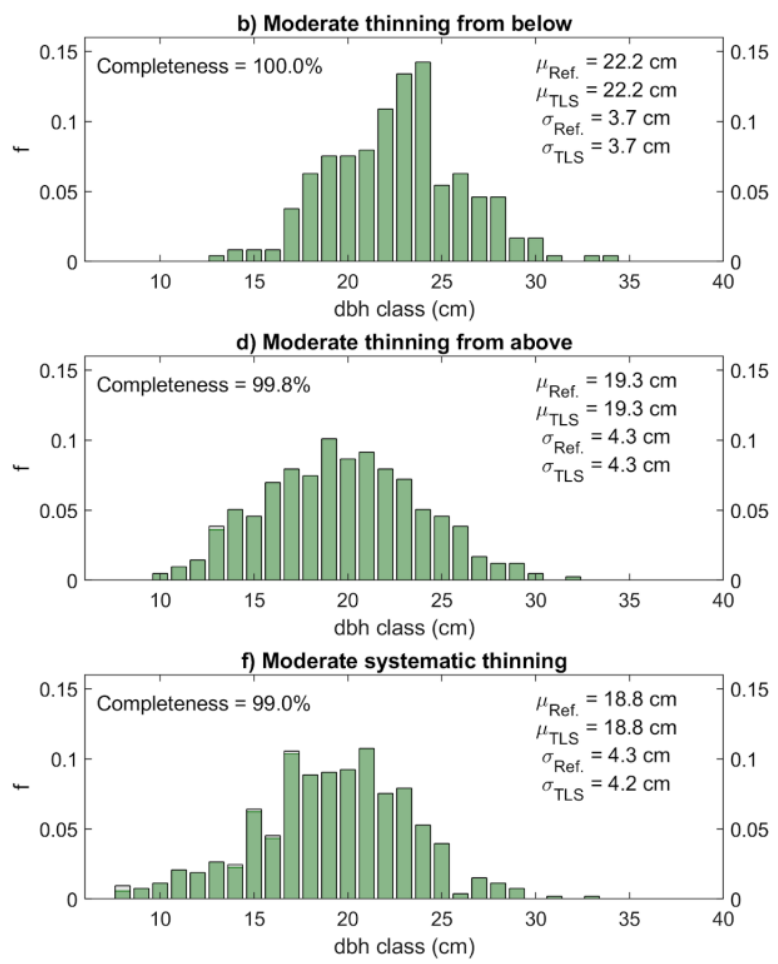

h) Normal distributions

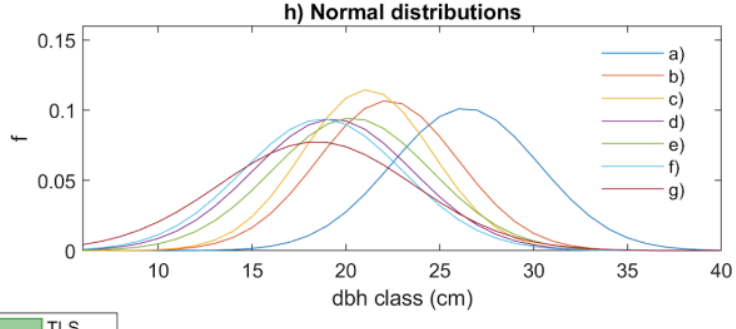

Fig. 3. Diameter-at-breast-height ( $\mathrm{dbh}$ ) distributions presenting the relative frequency ( $\mathrm{f}$ ) of trees in $1 \mathrm{~cm} d b h$ classes for each thinning treatment (a-g). The coloured bars represent the proportion of trees that were detected from the terrestrial laser scanning point clouds. For comparison, the dbh distributions are described as continuous normal distributions with parameters ( $\mu=$ mean value, $\sigma=$ standard deviation) extracted from the field-measured dbh distributions. 
This is a non-peer reviewed preprint submitted to EarthArXiv

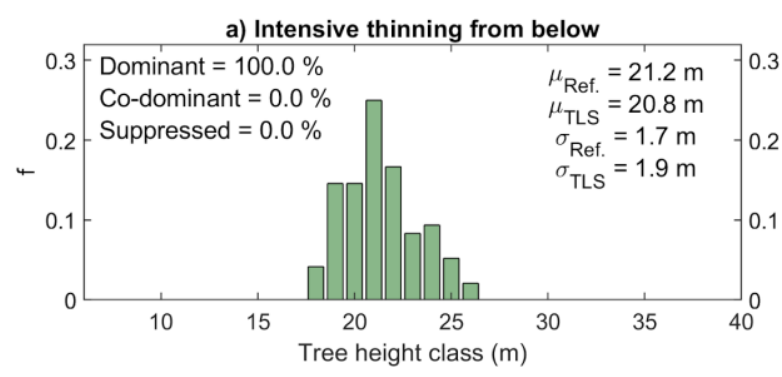

c) Intensive thinning from above

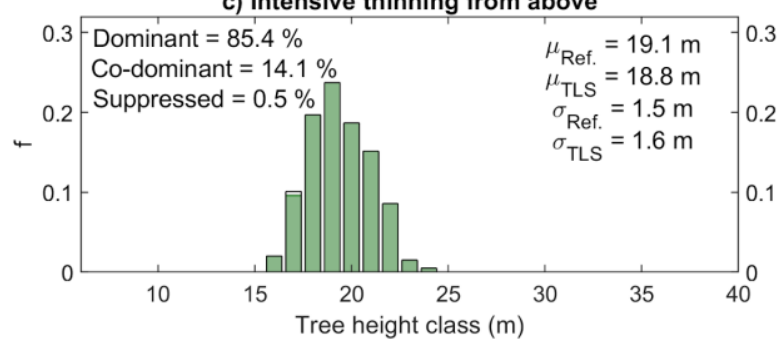

e) Intensive systematic thinning

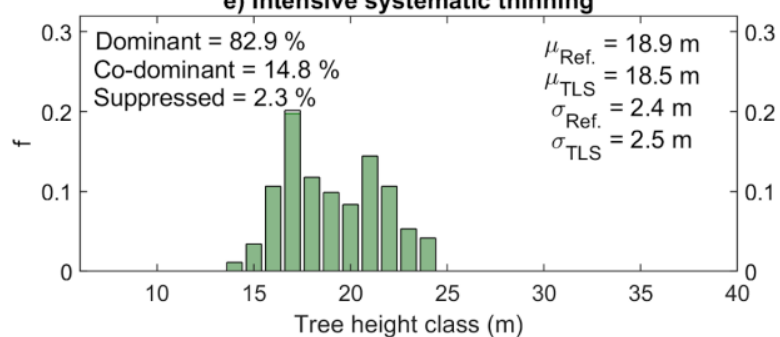

g) Control

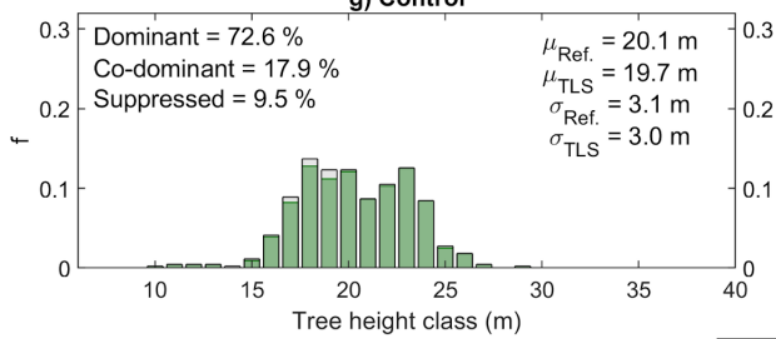

b) Moderate thinning from below

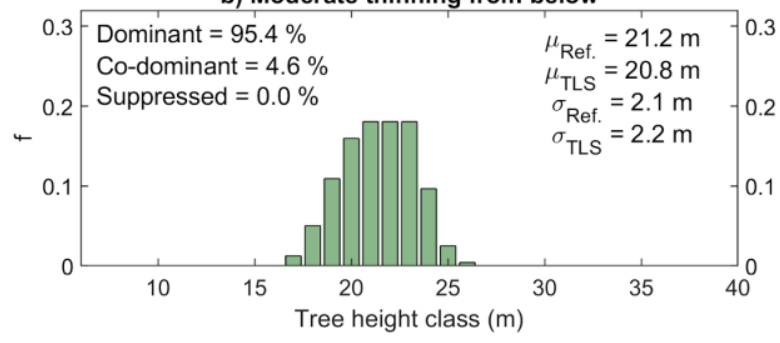

d) Moderate thinning from above

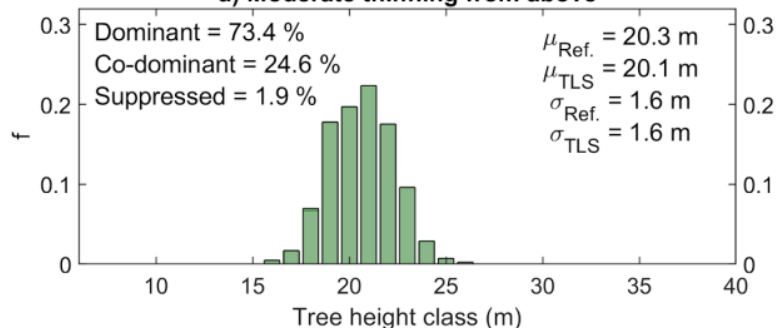

f) Moderate systematic thinning

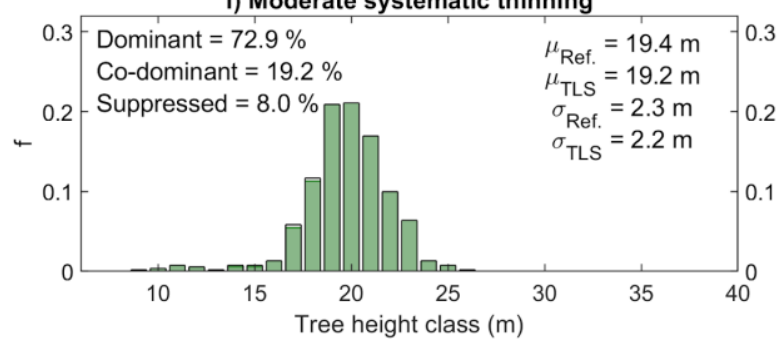

h) Tree height distributions

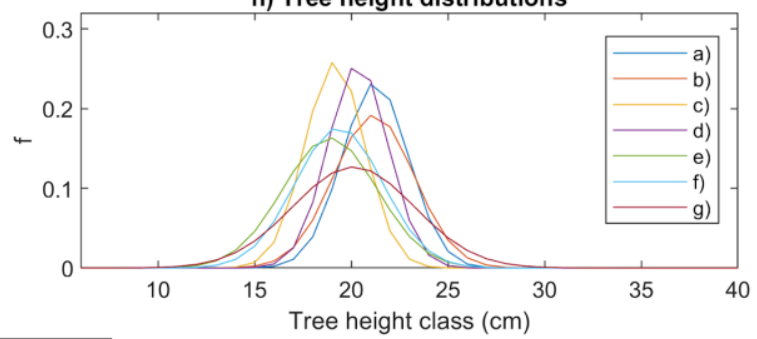

Fig. 4. Tree height distributions presenting the relative frequency (f) of trees in $1 \mathrm{~m}$ tree height classes for each thinning treatment $(\mathrm{a}-\mathrm{g})$. The coloured bars represent the proportion of trees that were detected from the terrestrial laser scanning point clouds. For comparison, the tree height distributions are described as normal distributions with parameters ( $\mu=$ mean value, $\sigma=$ standard deviation) extracted from the fieldmeasured tree height distribution. Proportions of trees on different canopy layers are reported for each thinning treatment $(\mathrm{a}-\mathrm{g})$.

Accuracy in dbh estimates remained consistent between thinning types (RMSE\% 3.0-3.4\%) as the only significant difference $(p<0.05)$ was found in estimation error between thinning from below and systematic thinning (Table 3) whereas the accuracy in tree height estimates varied between thinning types (RMSE\% 4.5$7.3 \%$ and significant difference between thinning from below and two other thinning types). Bias in tree height estimates was at the same level for thinning from below and control plots $(-2.0 \%$ and $-2.4 \%$, respectively), and for thinning from above and systematic thinning $(-1.4 \%$ and $-1.3 \%$, respectively). RMSE in tree height estimates varied between $0.89 \mathrm{~m}$ to $2.22 \mathrm{~m}$ being lowest for thinning from above and highest for control plots.

$D_{g}$ was estimated with similar accuracy throughout the thinning types (inc. control plots), while the accuracy of estimates for other forest structural attributes varied more between different thinning types (Table 3). Accuracy of the estimates for $\mathrm{H}_{\mathrm{g}}, \mathrm{G}, \mathrm{TPH}$, and $\mathrm{V}_{\text {mean }}$ differed when comparing the accuracy measures from control plots with the thinned plots. No significant differences $(p>0.05)$ in accuracy for $D_{g}, H_{g}$, $G$ and $V_{\text {mean }}$ estimates were found between thinning types (Table 3$)$. The errors of TPH, on the other hand, differed significantly $(p<0.05)$ between thinning types. 
This is a non-peer reviewed preprint submitted to EarthArXiv

Table 3. Bias and root-mean-square-error (RMSE) of estimates of tree and forest structural attributes on sample plots from different thinning types. Negative bias denotes underestimation. The highlighted $p$-values indicate significant differences $(<0.05)$ in the mean errors of the tree/forest attribute estimates between sample plots from different thinning types. $\mathrm{dbh}=$ diameter-at-breast-height, $\mathrm{D}_{\mathrm{g}}=$ basal area-weighted mean diameter $(\mathrm{cm}), \mathrm{H}_{\mathrm{g}}=$ basal area-weighted mean height $(\mathrm{m}), \mathrm{G}=$ mean basal area $\left(\mathrm{m}^{2} / \mathrm{ha}\right), \mathrm{TPH}=$ trees per hectare, $(\mathrm{n} / \mathrm{ha})$ and $\mathrm{V}_{\text {mean }}=$ mean volume $\left(\mathrm{m}^{3} / \mathrm{ha}\right)$.

\begin{tabular}{|c|c|c|c|c|c|c|c|}
\hline \multirow{2}{*}{$\begin{array}{c}\text { Tree / Forest } \\
\text { Attribute }\end{array}$} & \multirow[b]{2}{*}{ Thinning type } & \multicolumn{2}{|c|}{ Accuracy measures } & \multicolumn{4}{|c|}{$\begin{array}{l}\text { Significance of error differences } \\
\text { between thinning types ( } p \text {-values) }\end{array}$} \\
\hline & & Bias & RMSE & Below & Above & Syst. & Control \\
\hline \multirow{4}{*}{$d b h(\mathrm{~cm})$} & Thinning from below & $-0.20(-0.8 \%)$ & $0.70(3.0 \%)$ & 1 & 0.056 & 0.009 & 0.000 \\
\hline & Thinning from above & $-0.13(-0.6 \%)$ & $0.63(3.2 \%)$ & - & 1 & 0.285 & 0.004 \\
\hline & Systematic thinning & $-0.10(-0.5 \%)$ & $0.65(3.4 \%)$ & - & - & 1 & 0.044 \\
\hline & Control & $-0.06(-0.3 \%)$ & $0.76(4.1 \%)$ & - & - & - & 1 \\
\hline \multirow{4}{*}{ Tree height (m) } & Thinning from below & $-0.42(-2.0 \%)$ & $1.28(6.1 \%)$ & 1 & 0.045 & 0.014 & 0.362 \\
\hline & Thinning from above & $-0.28(-1.4 \%)$ & $0.89(4.5 \%)$ & - & 1 & 0.359 & 0.000 \\
\hline & Systematic thinning & $-0.25(-1.3 \%)$ & $1.41(7.3 \%)$ & - & - & 1 & 0.000 \\
\hline & Control & $-0.48(-2.4 \%)$ & $2.22(11.0 \%)$ & - & - & - & 1 \\
\hline \multirow{4}{*}{$D_{g}(\mathrm{~cm})$} & Thinning from below & $-0.34(-1.3 \%)$ & $0.43(1.7 \%)$ & 1 & 0.460 & 0.251 & 0.092 \\
\hline & Thinning from above & $-0.24(-1.1 \%)$ & $0.30(1.4 \%)$ & - & 1 & 0.399 & 0.053 \\
\hline & Systematic thinning & $-0.18(-0.9 \%)$ & $0.31(1.4 \%)$ & - & - & 1 & 0.269 \\
\hline & Control & $0.09(0.4 \%)$ & $0.23(1.1 \%)$ & - & - & - & 1 \\
\hline \multirow{4}{*}{$H_{g}(\mathrm{~m})$} & Thinning from below & $-0.46(-2.1 \%)$ & $0.55(2.6 \%)$ & 1 & 0.480 & 0.856 & 0.049 \\
\hline & Thinning from above & $-0.35(-1.7 \%)$ & $0.45(2.2 \%)$ & - & 1 & 0.486 & 0.004 \\
\hline & Systematic thinning & $-0.43(-2.1 \%)$ & $0.46(2.3 \%)$ & - & - & 1 & 0.000 \\
\hline & Control & $-0.82(-3.8 \%)$ & $1.07(5.0 \%)$ & - & - & - & 1 \\
\hline \multirow{4}{*}{$G\left(\mathrm{~m}^{2} / \mathrm{ha}\right)$} & Thinning from below & $-0.50(-2.3 \%)$ & $0.64(2.9 \%)$ & 1 & 0.982 & 0.603 & 0.002 \\
\hline & Thinning from above & $-0.51(-2.3 \%)$ & $0.57(2.5 \%)$ & - & 1 & 0.322 & 0.000 \\
\hline & Systematic thinning & $-0.41(-1.9 \%)$ & $0.51(2.4 \%)$ & - & - & 1 & 0.000 \\
\hline & Control & $-1.58(-4.2 \%)$ & $1.70(4.5 \%)$ & - & - & - & 1 \\
\hline \multirow{4}{*}{$T P H(\mathrm{n} / \mathrm{ha})$} & Thinning from below & $-1.35(-0.3 \%)$ & $3.31(0.7 \%)$ & 1 & 0.029 & 0.003 & 0.000 \\
\hline & Thinning from above & $-5.44(-0.8 \%)$ & $8.25(1.2 \%)$ & - & 1 & 0.246 & 0.000 \\
\hline & Systematic thinning & $-8.41(-1.2 \%)$ & $13.40(1.9 \%)$ & - & - & 1 & 0.000 \\
\hline & Control & $-82.32(-6.3 \%)$ & $98.67(7.5 \%)$ & - & - & - & 1 \\
\hline \multirow{4}{*}{$V_{\text {mean }}\left(\mathrm{m}^{3} / \mathrm{ha}\right)$} & Thinning from below & $6.24(2.8 \%)$ & $13.36(5.9 \%)$ & 1 & 0.804 & 0.907 & 0.022 \\
\hline & Thinning from above & $7.62(3.5 \%)$ & $10.37(4.8 \%)$ & - & 1 & 0.789 & 0.000 \\
\hline & Systematic thinning & $6.88(3.3 \%)$ & $11.21(5.4 \%)$ & - & - & 1 & 0.000 \\
\hline & Control & $-11.04(-2.8 \%)$ & $20.36(5.2 \%)$ & - & - & - & 1 \\
\hline
\end{tabular}


This is a non-peer reviewed preprint submitted to EarthArXiv

Variation in tree detection rate (i.e. completeness) varied from $0.0 \%$ to $2.3 \%$ between thinning treatments (Fig $5 \mathrm{~h})$. When no thinning treatments were carried out the variation in tree detection rate was $8.2 \%$.

Variation in dbh estimation error was similar regardless of the applied thinning type or intensity (Fig. 5a). For tree height estimates, smaller variation in the estimation error was recorded in intensively thinned sample plots (Fig. 5b). Variation in tree height estimation error was the largest for the sample plots with the most variation in tree size distribution (i.e., control plots and sample plots with moderate systematic thinning, see Figs. 3f-g, $4 f-g)$.

Variation in errors of $D_{g}$ estimates was similar between thinning type and intensity as well as control plots (Fig. $5 \mathrm{c})$. When estimating $\mathrm{H}_{\mathrm{g}}, \mathrm{G}, \mathrm{TPH}$, and $\mathrm{V}_{\text {mean }}$, the variation in estimation errors was significantly $(p<0.05)$ smaller for thinned plots than for control plots (Fig. $5 \mathrm{~d}-\mathrm{g}$ ). The error in $G$ and $V_{\text {mean }}$ estimates varied less in the sample plots with intensive thinning. The same applied with $\mathrm{H}_{\mathrm{g}}$ except for sample plots with thinning from above where moderate thinning intensity resulted in smaller variation in the estimation errors (Fig. $5 \mathrm{~d}$ ).
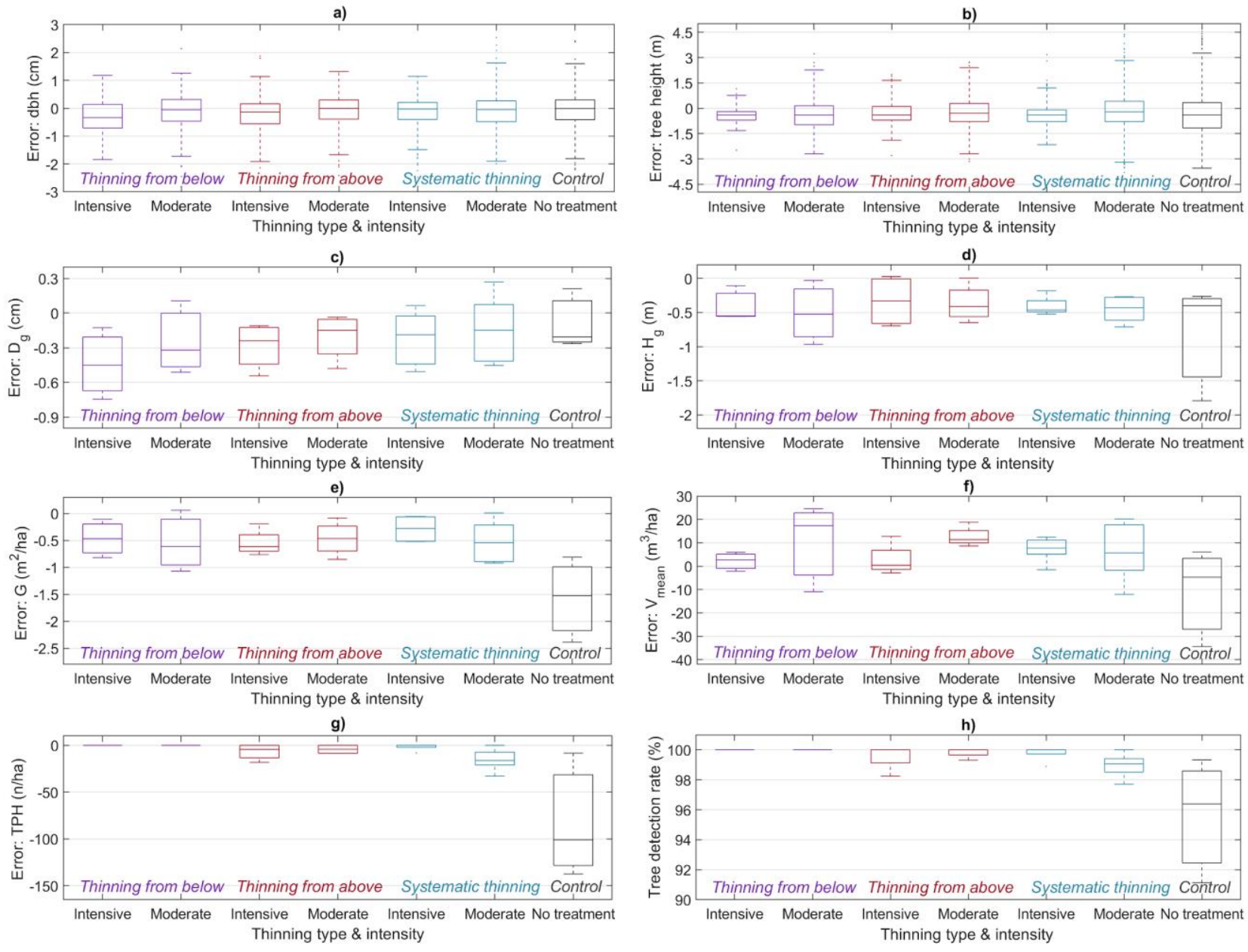

Fig. 5. Variation in estimation errors of tree attributes $(a-b)$, plot-level forest structural attributes $(c-g)$ and tree detection rate $(h)$ between different thinning treatments. $d b h=$ diameter-at-breast-height, $D_{g}=$ basal areaweighted mean diameter $(\mathrm{cm}), \mathrm{H}_{\mathrm{g}}=$ basal area-weighted mean height $(\mathrm{m}), \mathrm{G}=$ mean basal area $\left(\mathrm{m}^{2} / \mathrm{ha}\right)$,

$\mathrm{TPH}=$ trees per hectare, $(\mathrm{n} / \mathrm{ha})$ and $\mathrm{V}_{\text {mean }}=$ mean volume $\left(\mathrm{m}^{3} / \mathrm{ha}\right)$.

\section{DISCUSSION}

The objective of this study was to examine the effects of different thinning treatments on the performance of multi-scan TLS-based forest characterization in managed Scots pine stands. Different thinning treatments implemented to similar forest stands in 2005 and 2006 resulted in different forest structures 13 growing seasons later (Figs. 3-4). According to the results of this study, the accuracy of using the TLS-based approach for detecting trees, measuring tree heights, and estimating forest structural attributes (i.e. $\mathrm{H}_{\mathrm{g}}, \mathrm{TPH}, \mathrm{G}$, and 
This is a non-peer reviewed preprint submitted to EarthArXiv

$V_{\text {mean }}$ ) varied between the treatments due to differences in tree size distributions (Table 3). Thinning treatments in general explained most of the variation in the accuracy measures between all the sample plots. On control plots, where no thinnings were carried out, the accuracy was at a lower level and varied more than it did for sample plots with thinning treatments (Fig. 5). The TLS-based approach provided the most consistent estimates for $\mathrm{H}_{\mathrm{g}}, \mathrm{G}$, and $\mathrm{V}_{\text {mean }}$ on intensively thinned sample plots.

Forests were characterized accurately when the TLS-based method was applied in managed Scots pine stands where forest management activities had been carried out. Almost $100 \%$ completeness in tree detection, $0.7 \mathrm{~cm}$ RMSE in dbh estimates, and 0.9-1.4 m RMSE in tree height estimates were obtained depending on the applied thinning type (Table 3). These results are in line with the previous findings on the performance of TLS-based methods in characterizing trees in stands with relatively simple forest structure. Based on the existing knowledge, almost all the trees can be detected and dbh estimated with an accuracy of a few centimetres when the TLS-based method is applied to single-layered temperate (Bauwens et al., 2016; Koreň et al., 2017; Ritter et al., 2017) or boreal forests (Liang et al., 2018; Olofsson \& Holmgren, 2016; Saarinen et al., 2017). However, measuring the tree height correctly using multi-scan TLS has been recognized as a major challenge due to the hemispherical scanning geometry and thus, several meters of error in tree height estimates of conifers in boreal forests can be expected (Liang et al., 2016, 2018; Y. Wang et al., 2019). Nevertheless, the results of this study demonstrate that also tree height can reliably be estimated when the visibility from the scanner to the treetops is adequate. Considering the accuracy of tree attribute estimates, it should be noted that the accuracy obtained here with the TLS-based approach was close to the realized precision of the reference measurements, as a precision of $0.3 \mathrm{~cm}$ for $\mathrm{dbh}$ and $0.5 \mathrm{~m}$ for tree height is expected in similar boreal forest conditions when using callipers and clinometers to measure the tree attributes (Luoma et al., 2017).

Tree detection rate and tree height estimation accuracy varied between the sample plots due to variation in horizontal and vertical forest structure. Tree detection accuracy was noticed to decrease when no thinnings were carried out in the sample plots. It is known that tree detection accuracy is mostly affected by occlusion which is caused by vegetation density (Abegg et al., 2017; Yrttimaa, Saarinen, Kankare, et al., 2019), since trees behind other trees and bushes cannot be recorded. Using the multi-scan approach in TLS data acquisition decreases the number of occluded trees (Bauwens et al., 2016; Liang et al., 2016), but with a fixed scan setup and the lack of undergrowth vegetation in the study sites of this study, variation in tree detection accuracy between the sample plots is explained mainly by the variation in tree size distributions. According to the results of this study, most of the trees that were not detected were small (in terms of dbh and height) and suppressed. The smaller the tree was, the less the stem surface was directly visible for the scanner and, the more likely it was that it remained occluded by other trees. Then, after being detected from the point clouds, successful tree height estimation requires that the top of the tree crowns has been visible to the scanner and that the tree crowns have been correctly delineated. Intensive thinnings led to a sparser forest structure with improved visibility to the treetops, more clearly separable tree crowns, and a smaller number of trees in lower canopy layers (see Fig. 4). Thus, the tree height estimates were more accurate and the estimates remained more consistent on intensively thinned sample plots (Fig. 5).

Accuracy and consistency in tree detection and characterization led to a small variation in the plot-level forest structural attributes. By definition, TPH, G, and $\mathrm{V}_{\text {mean }}$ are computed by summing up the respective tree-level attributes at the plot level and thus, the accuracy of those estimates is linked with the accuracy in tree detection and tree attribute estimates. It is crucial to detect all trees from sample plots to extract unbiased estimates for TPH. In addition, dbh estimates should be accurate to ensure high accuracy for $G$ estimates. On top of that, accurate $V_{\text {mean }}$ estimates require that stem taper curves are estimated accurately to obtain reliable stem volume estimates which in turn also requires accurate tree height estimates. In general, accurate tree reconstruction requires that points representing a tree are classified based on their origin, in other words from stem, branches, and foliage. The algorithms developed in this study showed robust performance in accurately detecting trees, classifying point clouds, and estimating tree and forest structural attributes. This study verifies their performance in managed boreal forests, and the presented level of accuracy in forest characterization is expected to be maintained when applied in similar forest conditions. The other plot-level forest structural attributes, $\mathrm{D}_{g}$ and $\mathrm{H}_{\mathrm{g}}$ are less sensitive to accurate tree detection as they are computed as a weighted mean 
This is a non-peer reviewed preprint submitted to EarthArXiv

of tree attributes. With accurate dbh and tree height estimates, $\mathrm{D}_{g}$ and $\mathrm{H}_{g}$ can be estimated accurately even with a rather poor tree detection rate especially if the tree size distribution of detected trees represents the actual tree size distribution. These fundamentals in plot-level forest characterization can be seen in the results of this study (Fig. 5) as lower tree detection rate and tree height estimation accuracy caused bias to TPH, G, and $V_{\text {mean }}$ especially for control plots.

Performance of the TLS-based method in characterizing managed forest stands varied depending on the forest structure, which was caused by different controlled thinning treatments in our study. The accuracy measures varied between thinning intensity and type. The differences can be explained by the behaviour of the TLSbased method when the forest structure varies. The applied thinning treatments shaped the tree size distributions causing variation in both vertical and horizontal forest structure (Figs. 3-4). Most of the trees that remained undetected were suppressed trees, and the accuracy in dbh and tree height estimates were lower for them. Thus, it is reasonable to assume that an increase in the proportion of suppressed trees indicates declined overall accuracy of the TLS-based method in Scots pine stands. The proportion of suppressed trees increased when tree size variation increased, which explains the variation in the accuracy measures between different thinning treatments. The less there was variation in tree size distribution, the more similar the forest structure was between the sample plots where the same thinning treatment had been applied. Therefore, more consistent results were obtained for sample plots with less tree size variation. To sum up, the results of this study support the earlier findings by (Liang et al., 2018; Yrttimaa, Saarinen, Kankare, et al., 2019) that high accuracy in TLS-based forest characterization is guaranteed in forest stands with a low degree of tree size variation.

In general, consistent accuracy was obtained with the TLS-based method when estimating the forest structural attributes for thinned forest stands. The thinning intensity had more effect on the accuracy than thinning type, which emphasizes the link between forest density and performance of the TLS-based method. Differences in accuracy between the different thinning types were minor, which demonstrates that implementing different thinning types to similar forest stands did not eventually change the horizontal and vertical forest structure so much that it would considerably affect the tree detection, dbh estimation, and tree height estimation accuracy. All the tree size distributions were unimodal, and only the mean and standard deviation of the distributions differed between the treatments (Figs. 3-4). At the age of around 50 years, the investigated forest stands are still growing, and thus differences in the tree size distributions may be more distinct after another ten years. However, the results of this study demonstrate that higher accuracy is expected to be obtained with the TLSbased method if the overall density of trees and especially the proportion of suppressed trees is decreased with thinnings.

\section{CONCLUSIONS}

In this study, we examined how forest structure affects TLS-based forest characterization by using state-ofthe-art point cloud processing techniques and sample plots with controlled variation in forest structure. With almost $100 \%$ completeness in tree detection, $0.7 \mathrm{~cm}$ (3.4\%) RMSE in dbh measurements, 0.9-1.4 m (4.5$7.3 \%$ ) RMSE in tree height measurements, and less than $6 \%$ relative RMSE in the estimates of forest structural attributes, we conclude that high accuracy in characterizing trees and tree communities was achieved when applying the TLS-based approach in managed Scots pine stands where forest management activities had been carried out. The number of trees per hectare and the proportion of suppressed trees were recognized as the main factors affecting the accuracy of TLS-based forest characterization, and those factors can typically be controlled in managed forests. Thinning decreased variation in horizontal and vertical forest structure which favours TLS-based tree detection and tree height estimation, enabling reliable estimates for forest structural attributes.

The more variation there was in the tree size distribution, the more challenging it was for the TLS-based method to reliably capture all the trees and estimate the tree attributes and forest structural attributes. In general, consistent performance can be expected when using the TLS-based method in characterizing managed forest stands. A significantly lower performance was recorded on control plots where no treatments had been carried out. Thinning intensity had more effects on the accuracy of TLS-based forest characterization than thinning 
This is a non-peer reviewed preprint submitted to EarthArXiv

type. The use of intensive thinnings resulted in a spacious canopy structure which reduced errors in tree height estimates due to improved visibility from the scanner to the treetops. Intensive thinnings also decreased the variation in tree size distribution and thus enabled more consistent performance in forest characterization using TLS.

\section{ACKNOWLEDGEMENTS}

This research was funded by the Academy of Finland, grant numbers 315079 ("The effects of stand dynamics on tree architecture of Scots pine trees") and 272195 ("Centre of Excellence in Laser Scanning Research").

\section{DECLARATION OF INTEREST}

The authors declare no conflict of interest.

\section{REFERENCES}

Abegg, M., Kükenbrink, D., Zell, J., Schaepman, M., \& Morsdorf, F. (2017). Terrestrial Laser Scanning for Forest Inventories-Tree Diameter Distribution and Scanner Location Impact on Occlusion. In Forests (Vol. 8, Issue 6, p. 184). https://doi.org/10.3390/f8060184

Åkerblom, M., Raumonen, P., Kaasalainen, M., \& Casella, E. (2015). Analysis of Geometric Primitives in Quantitative Structure Models of Tree Stems. In Remote Sensing (Vol. 7, Issue 4, pp. 4581-4603). https://doi.org/10.3390/rs70404581

Aschoff, T., Thies, M., \& Spiecker, H. (2004). Describing forest stands using terrestrial laser-scanning. International Archives of Photogrammetry, Remote Sensing and Spatial Information Sciences, 35(5), 237-241.

Bauwens, S., Bartholomeus, H., Calders, K., \& Lejeune, P. (2016). Forest Inventory with Terrestrial LiDAR: A Comparison of Static and Hand-Held Mobile Laser Scanning. In Forests (Vol. 7, Issue 12, p. 127). https://doi.org/10.3390/f7060127

Bolles, R. C., \& Fischler, M. A. (1981). A RANSAC-based approach to model fitting and its application to finding cylinders in range data. Proceedings of the 7th International Joint Conference on Artificial Intelligence, 637-643.

Cabo, C., Ordóñez, C., López-Sánchez, C. A., \& Armesto, J. (2018). Automatic dendrometry: Tree detection, tree height and diameter estimation using terrestrial laser scanning. In International Journal of Applied Earth Observation and Geoinformation (Vol. 69, pp. 164-174). https://doi.org/10.1016/j.jag.2018.01.011

Côté, J.-F., Fournier, R. A., Frazer, G. W., \& Olaf Niemann, K. (2012). A fine-scale architectural model of trees to enhance LiDAR-derived measurements of forest canopy structure. In Agricultural and Forest Meteorology (Vols. 166-167, pp. 72-85). https://doi.org/10.1016/j.agrformet.2012.06.007

Dassot, M., Constant, T., \& Fournier, M. (2011). The use of terrestrial LiDAR technology in forest science: application fields, benefits and challenges. In Annals of Forest Science (Vol. 68, Issue 5, pp. 959-974). https://doi.org/10.1007/s13595-011-0102-2

Disney, M. I., Boni Vicari, M., Burt, A., Calders, K., Lewis, S. L., Raumonen, P., \& Wilkes, P. (2018). Weighing trees with lasers: advances, challenges and opportunities. Interface Focus, 8(2), 20170048. https://doi.org/10.1098/rsfs.2017.0048

Gollob, C., Ritter, T., Wassermann, C., \& Nothdurft, A. (2019). Influence of Scanner Position and Plot Size on the Accuracy of Tree Detection and Diameter Estimation Using Terrestrial Laser Scanning on Forest Inventory Plots. In Remote Sensing (Vol. 11, Issue 13, p. 1602). https://doi.org/10.3390/rs11131602

Hackenberg, J., Morhart, C., Sheppard, J., Spiecker, H., \& Disney, M. (2014). Highly Accurate Tree Models Derived from Terrestrial Laser Scan Data: A Method Description. In Forests (Vol. 5, Issue 5, pp. 10691105). https://doi.org/10.3390/f5051069

Heinzel, J., \& Huber, M. (2016). Detecting Tree Stems from Volumetric TLS Data in Forest Environments with Rich Understory. In Remote Sensing (Vol. 9, Issue 1, p. 9). https://doi.org/10.3390/rs9010009

Isenburg, M. (2019). LAStools_Efficient LiDAR Processing Software, (version 181001 academic); rapidlasso GmbH: Gilching, Germany. http://rapidlasso.com/LAStools 
This is a non-peer reviewed preprint submitted to EarthArXiv

Koreň, M., Mokroš, M., \& Bucha, T. (2017). Accuracy of tree diameter estimation from terrestrial laser scanning by circle-fitting methods. In International Journal of Applied Earth Observation and Geoinformation (Vol. 63, pp. 122-128). https://doi.org/10.1016/j.jag.2017.07.015

Laasasenaho, J. 1982. Taper curve and volume functions for pine, spruce and birch. Seloste: männyn, kuusen ja koivun runkokäyrä- ja tilavuusyhtälöt. Communicationes Instituti Forestalis Fenniae 108. 74 p.

Liang, X., Hyyppä, J., Kaartinen, H., Lehtomäki, M., Pyörälä, J., Pfeifer, N., Holopainen, M., Brolly, G., Francesco, P., Hackenberg, J., Huang, H., Jo, H.-W., Katoh, M., Liu, L., Mokroš, M., Morel, J., Olofsson, K., Poveda-Lopez, J., Trochta, J., ... Wang, Y. (2018). International benchmarking of terrestrial laser scanning approaches for forest inventories. In ISPRS Journal of Photogrammetry and Remote Sensing (Vol. 144, pp. 137-179). https://doi.org/10.1016/j.isprsjprs.2018.06.021

Liang, X., Kankare, V., Hyyppä, J., Wang, Y., Kukko, A., Haggrén, H., Yu, X., Kaartinen, H., Jaakkola, A., Guan, F., Holopainen, M., \& Vastaranta, M. (2016). Terrestrial laser scanning in forest inventories. In ISPRS Journal of Photogrammetry and Remote Sensing (Vol. 115, pp. 63-77). https://doi.org/10.1016/j.isprsjprs.2016.01.006

Liang, X., Litkey, P., Hyyppa, J., Kaartinen, H., Vastaranta, M., \& Holopainen, M. (2012). Automatic Stem Mapping Using Single-Scan Terrestrial Laser Scanning. In IEEE Transactions on Geoscience and Remote Sensing (Vol. 50, Issue 2, pp. 661-670). https://doi.org/10.1109/tgrs.2011.2161613

Luoma, V., Saarinen, N., Wulder, M., White, J., Vastaranta, M., Holopainen, M., \& Hyyppä, J. (2017). Assessing Precision in Conventional Field Measurements of Individual Tree Attributes. In Forests (Vol. 8, Issue 2, p. 38). https://doi.org/10.3390/f8020038

Maas, H. -G, -G. Maas, H., Bienert, A., Scheller, S., \& Keane, E. (2008). Automatic forest inventory parameter determination from terrestrial laser scanner data. In International Journal of Remote Sensing (Vol. 29, Issue 5, pp. 1579-1593). https://doi.org/10.1080/01431160701736406

Meyer, F., \& Beucher, S. (1990). Morphological segmentation. In Journal of Visual Communication and Image Representation (Vol. 1, Issue 1, pp. 21-46). https://doi.org/10.1016/1047-3203(90)90014-m

Morsdorf, F., Kükenbrink, D., Schneider, F. D., Abegg, M., \& Schaepman, M. E. (2018). Close-range laser scanning in forests: towards physically based semantics across scales. Interface Focus, 8(2), 20170046. https://doi.org/10.1098/rsfs.2017.0046

Newnham, G. J., Armston, J. D., Calders, K., Disney, M. I., Lovell, J. L., Schaaf, C. B., Strahler, A. H., \& Mark Danson, F. (2015). Terrestrial Laser Scanning for Plot-Scale Forest Measurement. In Current Forestry Reports (Vol. 1, Issue 4, pp. 239-251). https://doi.org/10.1007/s40725-015-0025-5

Olofsson, K., \& Holmgren, J. (2016). Single Tree Stem Profile Detection Using Terrestrial Laser Scanner Data, Flatness Saliency Features and Curvature Properties. In Forests (Vol. 7, Issue 12, p. 207). https://doi.org/10.3390/f7090207

Olofsson, K., \& Olsson, H. (2018). Estimating tree stem density and diameter distribution in single-scan terrestrial laser measurements of field plots: a simulation study. In Scandinavian Journal of Forest Research (Vol. 33, Issue 4, pp. 365-377). https://doi.org/10.1080/02827581.2017.1368698

Popescu, S. C., \& Wynne, R. H. (2004). Seeing the Trees in the Forest. In Photogrammetric Engineering \& Remote Sensing (Vol. 70, Issue 5, pp. 589-604). https://doi.org/10.14358/pers.70.5.589

Rantala, S. (Ed.). (2011). Finnish forestry practice and management. Metsäkustannus, Helsinki.

Raumonen, P., Kaasalainen, M., Åkerblom, M., Kaasalainen, S., Kaartinen, H., Vastaranta, M., Holopainen, M., Disney, M., \& Lewis, P. (2013). Fast Automatic Precision Tree Models from Terrestrial Laser Scanner Data. In Remote Sensing (Vol. 5, Issue 2, pp. 491-520). https://doi.org/10.3390/rs5020491

Ritter, T., Schwarz, M., Tockner, A., Leisch, F., \& Nothdurft, A. (2017). Automatic Mapping of Forest Stands Based on Three-Dimensional Point Clouds Derived from Terrestrial Laser-Scanning. In Forests (Vol. 8, Issue 8, p. 265). https://doi.org/10.3390/f8080265

Saarinen, N., Kankare, V., Vastaranta, M., Luoma, V., Pyörälä, J., Tanhuanpää, T., Liang, X., Kaartinen, H., Kukko, A., Jaakkola, A., Yu, X., Holopainen, M., \& Hyyppä, J. (2017). Feasibility of Terrestrial laser scanning for collecting stem volume information from single trees. In ISPRS Journal of Photogrammetry and Remote Sensing (Vol. 123, pp. 140-158). https://doi.org/10.1016/j.isprsjprs.2016.11.012

Saarinen, N., Kankare, V., Yrttimaa, T., Viljanen, N., Honkavaara, E., Holopainen, M., Hyyppa, J., Huuskonen, S., Hynynen, J., \& Vastaranta, M. (2020). Assessing the effects of stand dynamics on stem growth allocation of individual Scots pine trees. In bioRxiv (p. 2020.03.02.972521).

https://doi.org/10.1101/2020.03.02.972521 
Vicari, M. B., Disney, M., Wilkes, P., Burt, A., Calders, K., \& Woodgate, W. (2019). Leaf and wood classification framework for terrestrial LiDAR point clouds. In Methods in Ecology and Evolution (Vol. 10, Issue 5, pp. 680-694). https://doi.org/10.1111/2041-210x.13144

Wang, D. (2020). Unsupervised semantic and instance segmentation of forest point clouds. ISPRS Journal of Photogrammetry and Remote Sensing: Official Publication of the International Society for Photogrammetry and Remote Sensing , 165, 86-97. https://doi.org/10.1016/j.isprsjprs.2020.04.020

Wang, Y., Lehtomäki, M., Liang, X., Pyörälä, J., Kukko, A., Jaakkola, A., Liu, J., Feng, Z., Chen, R., \& Hyyppä, J. (2019). Is field-measured tree height as reliable as believed - A comparison study of tree height estimates from field measurement, airborne laser scanning and terrestrial laser scanning in a boreal forest. In ISPRS Journal of Photogrammetry and Remote Sensing (Vol. 147, pp. 132-145). https://doi.org/10.1016/j.isprsjprs.2018.11.008

Wan, P., Wang, T., Zhang, W., Liang, X., Skidmore, A. K., \& Yan, G. (2019). Quantification of occlusions influencing the tree stem curve retrieving from single-scan terrestrial laser scanning data. In Forest Ecosystems (Vol. 6, Issue 1). https://doi.org/10.1186/s40663-019-0203-1

Wilkes, P., Lau, A., Disney, M., Calders, K., Burt, A., de Tanago, J. G., Bartholomeus, H., Brede, B., \& Herold, M. (2017). Data acquisition considerations for Terrestrial Laser Scanning of forest plots. In Remote Sensing of Environment (Vol. 196, pp. 140-153). https://doi.org/10.1016/j.rse.2017.04.030

Yrttimaa, T., Saarinen, N., Kankare, V., Liang, X., Hyyppä, J., Holopainen, M., \& Vastaranta, M. (2019). Investigating the Feasibility of Multi-Scan Terrestrial Laser Scanning to Characterize Tree Communities in Southern Boreal Forests. In Remote Sensing (Vol. 11, Issue 12, p. 1423). https://doi.org/10.3390/rs11121423

Yrttimaa, T., Saarinen, N., Luoma, V., Tanhuanpää, T., Kankare, V., Liang, X., Hyyppä, J., Holopainen, M., \& Vastaranta, M. (2019). Detecting and characterizing downed dead wood using terrestrial laser scanning. In ISPRS Journal of Photogrammetry and Remote Sensing (Vol. 151, pp. 76-90). https://doi.org/10.1016/j.isprsjprs.2019.03.007

Zhang, W., Wan, P., Wang, T., Cai, S., Chen, Y., Jin, X., \& Yan, G. (2019). A Novel Approach for the Detection of Standing Tree Stems from Plot-Level Terrestrial Laser Scanning Data. In Remote Sensing (Vol. 11, Issue 2, p. 211). https://doi.org/10.3390/rs11020211 